\title{
Adsorption behavior and mechanism of arsenate at Fe-Mn binary oxide/water interface
}

\author{
Gaosheng Zhanga,b, Huijuan Liu ${ }^{a}$, Ruiping Liu ${ }^{a}$, Jiuhui $\mathbf{Q u}^{\mathrm{a}, *}$ \\ a State key Laboratory of Environmental Aquatic Chemistry, Research Center for Eco-Environmental Sciences, Chinese Academy of Sciences, P.O. Box 2871, Beijing 100085, China \\ ${ }^{\mathrm{b}}$ Yantai Institute of Coastal Zone Research for Sustainable Development, Chinese Academy of Sciences, 26 Yinhai Road, Yantai, 264003 Shandong, China
}

\section{A R T I C L E I N F O}

\section{Article history:}

Received 27 August 2008

Received in revised form 17 December 2008

Accepted 16 February 2009

Available online 9 March 2009

\section{Keywords:}

Fe-Mn binary oxide

Arsenate

Adsorption mechanism

Specific adsorption

\begin{abstract}
A B S T R A C T
Preliminary study revealed that a prepared Fe-Mn binary oxide adsorbent with a Fe:Mn molar ratio of 3:1 was more effective for $\mathrm{As}(\mathrm{V})$ removal than pure amorphous $\mathrm{FeOOH}$, which was unanticipated. In this paper, the $\mathrm{As}(\mathrm{V})$ adsorption capacities of Fe-Mn binary oxide and amorphous FeOOH were compared in detail. Furthermore, the adsorption behaviors as well as adsorption mechanism of As(V) at the Fe-Mn binary oxide/water interface were investigated. The higher uptake of $\mathrm{As}(\mathrm{V})$ by the Fe-Mn binary oxide may be due to its higher surface area $\left(265 \mathrm{~m}^{2} / \mathrm{g}\right)$ and pore volume $\left(0.47 \mathrm{~cm}^{3} / \mathrm{g}\right)$ than those of amorphous FeOOH. The $\mathrm{As}(\mathrm{V})$ adsorption process on the Fe-Mn binary oxide is endothermic and the increase of temperature is favoring its adsorption. A slight increase in the $\mathrm{As}(\mathrm{V})$ adsorption was observed with increasing ionic strength of the solution, which indicated that $\mathrm{As}(\mathrm{V})$ anions might form inner-sphere surface complexes at the oxide/water interface. The Zeta potential along with FTIR analysis confirmed further the formation of inner-sphere surface complexes between $\mathrm{As}(\mathrm{V})$ anions and the surface of Fe-Mn binary oxide. In addition, the influences of coexisting ions such as phosphate, bicarbonate, silicate, sulfate, chloride, calcium and magnesium which are generally present in groundwater on $\mathrm{As}(\mathrm{V})$ adsorption were examined. Among the tested anions, chloride and sulfate had no significant effect on As(V) removal, silicate decreased obviously the $\mathrm{As}(\mathrm{V})$ removal, while phosphate caused the greatest percentage decrease in $\mathrm{As}(\mathrm{V})$ adsorption. On the contrary, the presence of cations of $\mathrm{Ca}^{2+}$ and $\mathrm{Mg}^{2+}$ enhanced the adsorption of $\mathrm{As}(\mathrm{V})$.
\end{abstract}

(c) 2009 Elsevier B.V. All rights reserved.

\section{Introduction}

Arsenic is a well-known highly toxic and carcinogenic element. Its contamination in aqueous system has been a serious concern throughout the world. Elevated concentrations of arsenic are found in the groundwater of many regions of countries around the world, such as Argentina, Bangladesh, Canada, Chile, China, India, Japan, Mongolia, Poland, Thailand, the United States, and Vietnam [1-4]. Arsenic is introduced into aquatic environment from both natural and manmade sources. Typically, however, arsenic occurrence in groundwater is caused by the weathering and dissolution of arsenic-bearing rocks, minerals, and ores [2]. Ingesting arseniccontaining water is extremely detrimental to human health. To protect public health, a much more stringent limit of concentration of $10 \mu \mathrm{g} / \mathrm{L}$ provided by World Health Organization (WHO) has been adopted as the drinking water standard by many countries.

Several methods such as precipitation, coprecipitation, ionexchange, adsorption, ultra filtration, and reverse osmosis are available to remove arsenic from water, among them adsorption

\footnotetext{
* Corresponding author. Tel.: +86 1062849151 ; fax: +86 1062923558 .

E-mail address: jhqu@mail.rcees.ac.cn (J. Qu).
}

process is proved to be cost-effective and simple to perform. Numerous materials [5] from natural ones to the specially designed have already been proposed for the adsorption of arsenic from water. The results of many studies [6-8] reveal that iron (hydr)oxides are promising sorbent materials because they have strong affinities towards inorganic arsenic species and high selectivity to arsenic in the sorption process. In addition, they are low cost and easily available. Therefore, much more researches are recently focused on removing arsenic with iron (hydr)oxides or iron-based materials as adsorbents. Dixit and Hering [7] have observed that amorphous iron hydroxide, goethite, and magnetite have high arsenic adsorption capacities. Zhang et al. [9] developed a Fe-Ce bimetal oxide adsorbent for arsenic removal. This adsorbent exhibited a significantly higher arsenate capacity than the individual $\mathrm{Ce}$ and $\mathrm{Fe}$ oxides $\left(\mathrm{CeO}_{2}\right.$ and $\left.\mathrm{Fe}_{3} \mathrm{O}_{4}\right)$ prepared by the same procedure. Mishra and Farrell [10] evaluated the arsenic removal using mixed valent iron oxides as adsorbents.

Though these adsorbents have relatively high adsorption capacities towards arsenate, they are not so effective for arsenite removal. Therefore, it is necessary to develop new adsorbents which are of low-cost and can effectively remove both arsenate and arsenite simultaneously. Recently, a novel Fe-Mn binary oxide adsorbent (with a Fe:Mn molar ratio of $3: 1$ ) has been synthesized by a 
simple and low cost method in our laboratory [11]. This adsorbent is aimed at enhancing arsenite removal since the present manganese dioxide could effectively oxidize arsenite to arsenate. Experimental results show that it is very effective for arsenite removal. It is expected that the presence of manganese dioxide will lower its arsenate removal efficiency because manganese dioxide has very low adsorption capacity to arsenate. However, preliminary result indicates the uptake of arsenate by this Fe-Mn binary oxide is higher than that by pure iron oxide. Thus, it is necessary to investigate the adsorption behaviors and mechanism of arsenate on this adsorbent.

The adsorption mechanism of arsenic on iron (hydr)oxides has also been investigated by a number of researchers using EXAFS and IR spectroscopic techniques and shows that arsenic forms binuclear bidentate as well as monodentae complexes on the iron oxide surface [12-15]. In addition to spectroscopic techniques, isoelectric point determinations have been used to verify specific or nonspecific adsorption of adsorbate ions on solid surfaces. Hingston et al. [16] observed a shift of isoelectric point of goethite with specifically adsorbed anions to lower value.

The main objectives of this research were (1) to compare the adsorption performance of arsenate on pure iron oxide and Fe-Mn binary oxide; (2) to study the kinetics and equilibrium of the adsorption of arsenate on the Fe-Mn binary oxide; and finally (3) to investigate arsenate adsorption mechanism.

\section{Materials and methods}

\subsection{Materials}

All chemicals used were analytical grade and were purchased from Beijing Chemical Co. (Beijing, China). The As(V) stock solution was prepared with deionized water using $\mathrm{NaHAsO}_{4} \cdot 7 \mathrm{H}_{2} \mathrm{O}$. Arsenic working solutions were freshly prepared by diluting arsenic solutions with deionized water. The concentrations of arsenic species were always given as elemental arsenic concentration in this study.

\subsection{Adsorbents preparation}

The Fe-Mn binary oxide with a Fe:Mn molar ratio of 3:1 was prepared according to the procedure published previously [11]. Potassium permanganate $\left(\mathrm{KMnO}_{4}, 0.015 \mathrm{~mol}\right)$ and iron(II) sulfate heptahydrate $\left(\mathrm{FeSO}_{4} \cdot 7 \mathrm{H}_{2} \mathrm{O}, 0.045 \mathrm{~mol}\right)$ were dissolved in $200 \mathrm{~mL}$ of deionized water, respectively. Under vigorous magnetic-stirring, the $\mathrm{FeSO}_{4}$ solution was slowly added into the $\mathrm{KMnO}_{4}$ solution, and $5 \mathrm{M} \mathrm{NaOH}$ solution was simultaneously added to keep the solution $\mathrm{pH}$ in the range of 7 and 8 . After addition, the formed suspension was continuously stirred for $1 \mathrm{~h}$, aged at room temperature for 12 hour and then washed repeatedly with deionized water until no $\mathrm{SO}_{4}{ }^{2-}$ was detected. The suspension was filtrated and dried at $105^{\circ} \mathrm{C}$ for $4 \mathrm{~h}$. The dry material was crushed and stored in a desiccator for use. The pure amorphous $\mathrm{FeOOH}$ adsorbent was synthesized using the following method: contacting $0.5 \mathrm{M} \mathrm{FeCl}_{3}$ with $1 \mathrm{M} \mathrm{NaOH}$, aging the formed suspension for $4 \mathrm{~h}$ and drying at $105^{\circ} \mathrm{C}$ for $24 \mathrm{~h}$. The prepared Fe-Mn binary oxide has been well characterized elsewhere.

\subsection{Batch adsorption tests}

The kinetics experiments were conducted in batch mode. Defined amount of $\mathrm{As}(\mathrm{V})$ stock solution was added in a $1000-\mathrm{mL}$ glass vessel containing $750 \mathrm{~mL} 0.01 \mathrm{M} \mathrm{NaNO}_{3}$ solution, to make $10 \mathrm{mg} / \mathrm{L}$ or $20 \mathrm{mg} / \mathrm{L}$ of $\mathrm{As}(\mathrm{V})$ concentration. After the solution $\mathrm{pH}$ was adjusted to 6.9 by adding $0.1 \mathrm{M} \mathrm{HCl}$ and/or $\mathrm{NaOH}, 0.15 \mathrm{~g}$ of $\mathrm{Fe}-\mathrm{Mn}$ binary oxide was added to obtain a $0.2 \mathrm{~g} / \mathrm{L}$ suspension. The suspension was mixed with a magnetic stirrer, and the $\mathrm{pH}$ was maintained at 6.9 throughout the experiment by addition of the dilute acid and/or base solutions. Approximately $5 \mathrm{~mL}$ aliquots were taken from the suspension at the following intervals: $0.083,0.167$, $0.25,0.333,0.67,1,1.5,2,4,7,11$ and $22 \mathrm{~h}$ of reaction. The samples were filtered through a $0.45 \mu \mathrm{m}$ membrane filter. The concentration of arsenate in the filtered solution was determined using an inductively coupled plasma atomic emission spectroscopy (ICP-OES).

Other adsorption tests were performed in $150 \mathrm{~mL}$ glass vessels. The effect of ionic strength of the solution on arsenate removal and $\mathrm{As}(\mathrm{V})$ adsorption isotherms were determined in batch tests. Experiments to determine the effect of ionic strength on arsenate removal were performed by adding $10 \mathrm{mg}$ of the adsorbent sample into the vessel, containing $50 \mathrm{~mL}$ of $10 \mathrm{mg} / \mathrm{L}$ arsenic solution. The $\mathrm{pH}$ of the solutions was adjusted every four hours with dilute $\mathrm{HCl}$ or/and $\mathrm{NaOH}$ solution to designated values in the range of 4-10 during shaking process. The equilibrium $\mathrm{pH}$ was measured and the supernatant was filtered through a $0.45 \mu \mathrm{m}$ membrane after the solutions were mixed for $24 \mathrm{~h}$. Adsorption isotherms of $\mathrm{As}(\mathrm{V})$ by pure amorphous $\mathrm{FeOOH}$ and $\mathrm{Fe}-\mathrm{Mn}$ binary oxide were determined at the equilibrium $\mathrm{pH}$ values of $6.9 \pm 0.1$. Initial arsenic concentrations were varied from $5 \mathrm{mg} / \mathrm{L}$ to $50 \mathrm{mg} / \mathrm{L}$. The influence of temperature on arsenate adsorption on the Fe-Mn binary oxide was carried out at $\mathrm{pH} 5.5 \pm 0.1$. In order to test the effects of coexisting ions on $\mathrm{As}(\mathrm{V})$ removal, ions concentrations ranged from $0.1 \mathrm{mM}$ to $10 \mathrm{mM}$. Ionic strength of the solution was adjusted to $0.01 \mathrm{M}$ with $\mathrm{NaNO}_{3}$. All batch experiments except for the test examining the effect of temperature on arsenate adsorption were carried out at $25 \pm 1{ }^{\circ} \mathrm{C}$ with an adsorbent content of $200 \mathrm{mg} / \mathrm{L}$ and all the suspensions were shaken on an orbit shaker at $140 \mathrm{rpm}$ for $24 \mathrm{~h}$. The quantity of adsorbed arsenic was calculated by the difference of the initial and residual amounts of arsenic in solution divided by the weight of the adsorbent.

\subsection{Analytical methods}

$\mathrm{As}(\mathrm{V})$ concentrations were determined using an inductively coupled plasma atomic emission spectroscopy (ICP-OES) (SCIEX PerkinElmer Elan mode 5000). Prior to analysis, the aqueous samples were acidified with concentrated $\mathrm{HCl}$ in an amount of $1 \%$, and stored in acid-washed glass vessels. All samples were analyzed within $24 \mathrm{~h}$ of collection.

\subsection{Characterization}

Specific surface area, pore volume, and pore size distribution were measured by nitrogen adsorption-desorption isotherm using the BET method with a Micromeritics ASAP 2000 surface area analyzer. X-ray diffraction (XRD) analysis was carried out on a $\mathrm{D} / \mathrm{Max}-3 \mathrm{~A}$ diffractometer using Ni-filtered copper $\mathrm{K} \alpha 1$ radiation for crystalline phase identification.

FTIR spectra were collected on a Nicolet 5700 FTIR spectrophotometer (Nicolet Co., USA) using transmission model. Samples for FTIR determination were ground with spectral grade $\mathrm{KBr}$ in an agate mortar. IR spectra of arsenate adsorbed on Fe-Mn binary oxide were obtained as dry samples in $\mathrm{KBr}$ pellets corresponding to $5 \mathrm{mg}$ of sample in approximately $200 \mathrm{mg}$ of spectral grade KBr. All IR measurements were carried out at room temperature.

AZeta potential analyzer (zetasizer 2000, Malvern, UK) was used to analyze the Zeta potential of Fe-Mn binary oxide particles before and after arsenate adsorption. The content of the Fe-Mn binary oxide in the solution is about $200 \mathrm{mg} / \mathrm{L}$ and $\mathrm{As}(\mathrm{V})$ concentration is $10 \mathrm{mg} / \mathrm{L} .0 .01 \mathrm{M} \mathrm{NaNO}_{3}$ was used as background electrolyte to maintain an approximately constant ionic strength. After adsorption equilibrium, $20 \mathrm{~mL}$ of oxide suspension was transferred to a sample tube. Zeta potential of the suspensions was then measured by electrokinetic analysis. 
Table 1

BET specific surface area and porosity measurements of amorphous FeOOH and Fe-Mn binary oxide.

\begin{tabular}{|c|c|c|c|}
\hline Adsorbent & Specific surface area $\left(\mathrm{m}^{2} / \mathrm{g}\right)$ & Average pore diameter $(\AA)$ & Average pore volume $\left(\mathrm{cm}^{3} / \mathrm{g}\right)$ \\
\hline Amorphous FeOOH & 247 & 40 & 0.25 \\
\hline Fe-Mn binary oxide (3:1) & 265 & 71 & 0.47 \\
\hline
\end{tabular}

\section{Results and discussion}

\subsection{Adsorbent characterization}

The specific surface area and pore volume of Fe-Mn binary oxide and pure amorphous $\mathrm{FeOOH}$ were determined by the surface area analyzer. The data are listed in Table 1 . The BET surface area of pure amorphous $\mathrm{FeOOH}$ is $247 \mathrm{~m}^{2} / \mathrm{g}$. This is in agreement to the results obtained by other researchers. For an example, Crosby et al. [17] reported that the surface area of amorphous FeOOH aged for $2 \mathrm{~h}$ to 12 days was $159-234 \mathrm{~m}^{2} / \mathrm{g}$. The Fe-Mn binary oxide has a high specific surface area of $265 \mathrm{~m}^{2} / \mathrm{g}$ with a pore volume of $0.47 \mathrm{~cm}^{3} / \mathrm{g}$ and the Fe oxide and $\mathrm{Mn}$ oxide of the Fe-Mn binary composite exist mainly in amorphous form [11]. The XRD pattern of pure iron (hydr)oxide adsorbent (not presented in this paper) showed that no obvious crystalline peak was detected, indicating its amorphous structure.

\subsection{Adsorption isotherms}

Preliminary study revealed that the prepared Fe-Mn binary oxide adsorbent was more effective for arsenate removal than pure amorphous FeOOH. To further compare their $\mathrm{As}(\mathrm{V})$ adsorption capacities, adsorption isotherms for $25^{\circ} \mathrm{C}$ were obtained at $\mathrm{pH}$ $6.9 \pm 0.1$ by varying the initial concentration of $A s(V)(5-50 \mathrm{mg} / \mathrm{L})$. The adsorption isotherms thus obtained are demonstrated in Fig. $1 \mathrm{a}$. As can be seen from the figure, the Fe-Mn binary oxide has a much higher adsorption capacity of $\mathrm{As}(\mathrm{V})$ than that of pure amorphous $\mathrm{FeOOH}$. The higher uptake of $\mathrm{As}(\mathrm{V})$ by the $\mathrm{Fe}-\mathrm{Mn}$ binary oxide is unexpected because manganese dioxide has very low adsorption capacity to arsenate and its presence in the adsorbent should lower the arsenate removal efficiency. The specific surface area and pore volume of these two adsorbents might account for this result. Generally, adsorbent with a high specific surface area has a high adsorption capacity. The specific surface area of the Fe-Mn binary oxide $\left(265 \mathrm{~m}^{2} / \mathrm{g}\right)$ is higher than that of amorphous $\mathrm{FeOOH}$ $\left(247 \mathrm{~m}^{2} / \mathrm{g}\right)$. Furthermore, the pore volume of the Fe-Mn binary oxide $\left(0.47 \mathrm{~cm}^{3} / \mathrm{g}\right)$ is remarkably larger than that of amorphous $\mathrm{FeOOH}\left(0.25 \mathrm{~cm}^{3} / \mathrm{g}\right)$. It is possible that the high specific area and pore volume enhance the $\mathrm{As}(\mathrm{V})$ adsorption performance of $\mathrm{Fe}-\mathrm{Mn}$ binary oxide. The Fe-Mn binary oxide has high potential to be used as adsorbent for arsenic removal, considering its high adsorption capacities towards both arsenate and arsenite [11].

Data from the adsorption isotherms were modeled using Freundlich and Langmuir isotherm models (only Freundlich type provided in Fig. 1a). It was found that both Freundlich and Langmuir models were suitable for describing the adsorption behavior of arsenate on amorphous FeOOH. However, for the Fe-Mn binary oxide, Freundlich model fitted the data better. This is perhaps due to the heterogeneity of the adsorbent surface with the presence of manganese dioxide. The Freundlich isotherm describes adsorption where the adsorbent has a heterogeneous surface with adsorption sites that have different energies of adsorption. The energy of adsorption varies as a function of the surface coverage and is represented by the Freundlich constant $K_{\mathrm{F}}(\mathrm{L} / \mathrm{g})$ in Eq. (1).

$Q_{\mathrm{e}}=K_{\mathrm{F}} C_{\mathrm{e}}^{1 / n}$

where $Q_{e}$ is the quantity of solute (arsenate) adsorbed per unit mass of adsorbent, $C_{\mathrm{e}}$ is the concentration of solute in the solution at
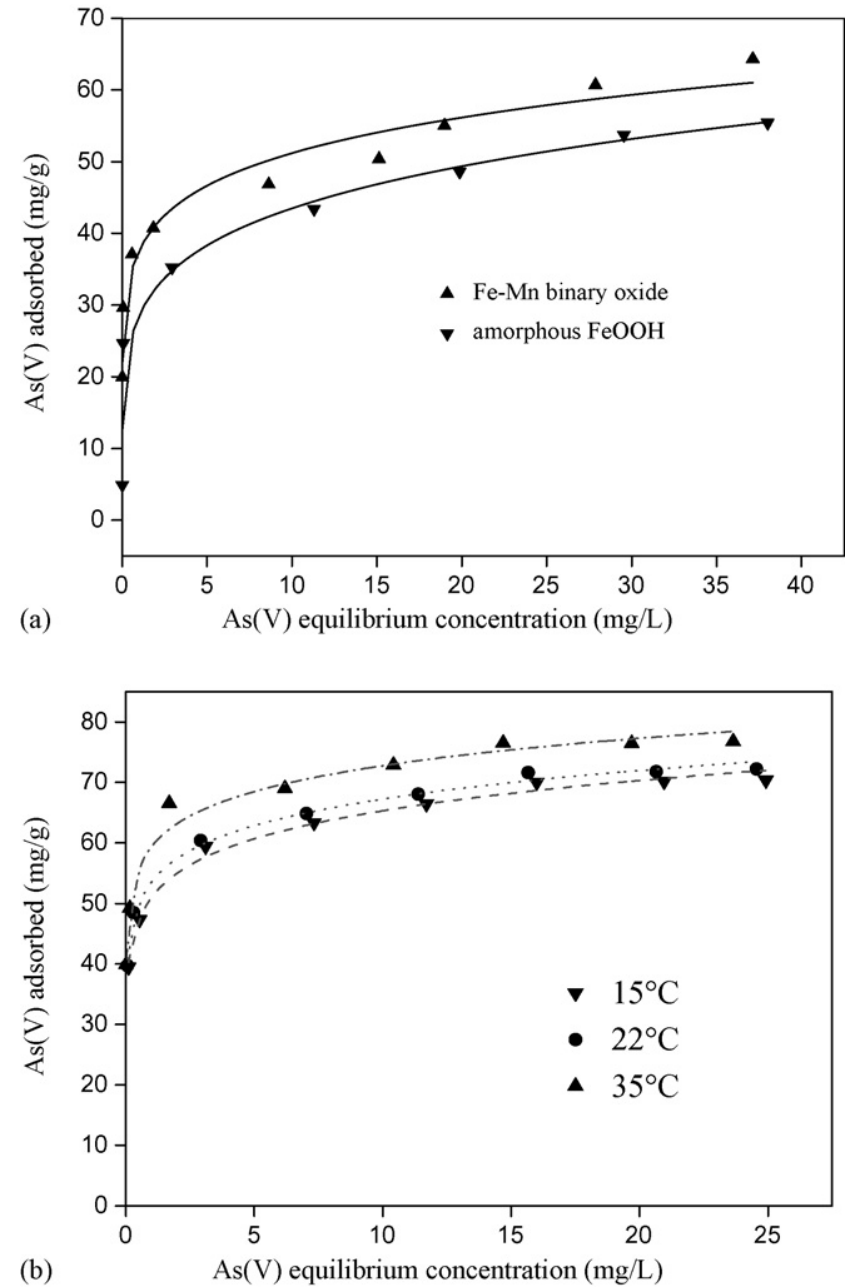

Fig. 1. Adsorption isotherms of $\mathrm{As}(\mathrm{V})$ (a) on amorphous FeOOH and Fe-Mn binary oxide in a $200 \mathrm{mg} / \mathrm{L}$ suspension at $\mathrm{pH} 6.9 \pm 0.1$ and $25 \pm 1{ }^{\circ} \mathrm{C}$, using the Freundlich model and (b) on Fe-Mn binary oxide at different temperatures in a $200 \mathrm{mg} / \mathrm{L}$ suspension at $\mathrm{pH} 5.5 \pm 0.1$, using the Freundlich model.

equilibrium, $K_{\mathrm{F}}$ is roughly an indicator of the adsorption capacity and $n$ is the heterogeneity factor which has a lower value for more heterogeneous surfaces.

The effect of three different temperatures $\left(15^{\circ} \mathrm{C}, 22^{\circ} \mathrm{C}, 35^{\circ} \mathrm{C}\right)$ on arsenate adsorption was examined at $\mathrm{pH} 5.5 \pm 0.1$ and was presented in Fig. 1b. The adsorption isotherms were fitted by Freundlich model. The values of $K_{\mathrm{F}}$ and $1 / n$ at different temperature are listed in Table 2. It was found that the adsorption capacity increased with increasing temperature which indicates that the adsorption

Table 2

Freundlich isotherm calculations.

\begin{tabular}{llll}
\hline \multirow{4}{*}{} & \multicolumn{2}{l}{ Fe-Mn binary oxide + As $(\mathrm{V})$} & $1 / n$ \\
\cline { 2 - 4 } & $R$ & $K_{\mathrm{F}}$ & 0.106 \\
$15^{\circ} \mathrm{C}$ & 0.9908 & 51.15 & 0.097 \\
$22^{\circ} \mathrm{C}$ & 0.9942 & 53.72 & 0.087 \\
$35^{\circ} \mathrm{C}$ & 0.9804 & 59.53 & \\
\hline
\end{tabular}




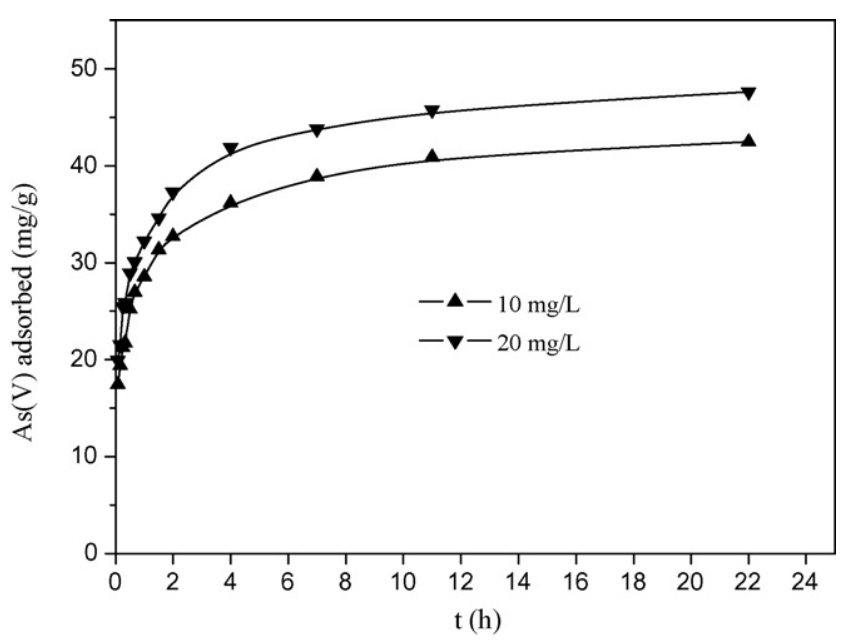

Fig. 2. Adsorption kinetics of arsenate on Fe-Mn binary oxide adsorbent in a $200 \mathrm{mg} / \mathrm{L}$ suspension at $\mathrm{pH} 6.9 \pm 0.1$ and two initial arsenic concentrations ( $10 \mathrm{mg} / \mathrm{L}$ and $20 \mathrm{mg} / \mathrm{L})$.

process is endothermic in nature. Therefore, the increase of temperature is favoring the arsenate removal by this adsorbent.

\subsection{Adsorption kinetics}

The adsorption kinetics of arsenate on the Fe-Mn binary oxide is illustrated in Fig. 2. The adsorption process could be divided into two steps, a quick step and a slow one. In the first step, the adsorption rate was fast, and over $80 \%$ of the equilibrium adsorption capacity was achieved within $3 \mathrm{~h}$. In the subsequent step, the adsorption was slow. After $11 \mathrm{~h}$, over $96 \%$ of the maximum adsorption had taken place, thus $24 \mathrm{~h}$ was an adequate time for equilibration to occur. Adsorption solely due to electrostatic processes is usually very rapid, in the order of seconds [6]. The adsorption of arsenate by the Fe-Mn binary oxide is on the order of hours, which may indicate a specific adsorption occurring between the arsenate species and the surface of the adsorbent.

\subsection{Influence of ionic strength on arsenate adsorption}

The effect of ionic strength of solution on the adsorption process of arsenate on the Fe-Mn binary oxide adsorbent is shown in Fig. 3.

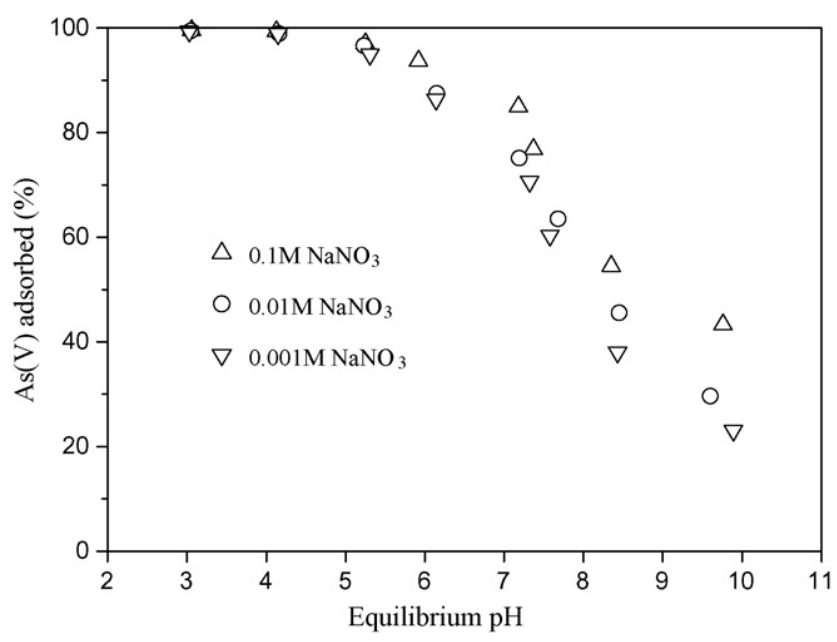

Fig. 3. Effect of $\mathrm{pH}$ on $\mathrm{As}(\mathrm{V})$ adsorption on Fe-Mn binary oxide for different ionic strengths. Initial $\mathrm{As}(\mathrm{V})$ concentration was $10 \mathrm{mg} / \mathrm{L}$ and adsorbent content was $200 \mathrm{mg} / \mathrm{L}$.
$\mathrm{NaNO}_{3}$ was adopted as electrolyte in this investigation. It was found that the increase in ionic strength from $0.001 \mathrm{M}$ to $0.1 \mathrm{M}$ led to a shift in the position of the $\mathrm{pH}$ edge towards the alkaline region, and also enhanced the adsorption of arsenate in this $\mathrm{pH}$ range (7-10). A similar phenomenon was observed by Deliyanni and coworkers [18] when they studied the adsorption of $\mathrm{As}(\mathrm{V})$ on akaganéite. Anions that adsorb by outer-sphere association are strongly sensitive to ionic strength and the adsorption of these anions is suppressed by competition with weakly adsorbing anions such as $\mathrm{NO}_{3}{ }^{-}$since electrolytes also form outer-sphere complexes through electrostatic forces. Conversely, anions that adsorb by inner-sphere association either show little sensitivity to ionic strength or respond to higher ionic strength with greater adsorption [19]. The results of this experiment suggest that arsenate anions may form inner-sphere surface complexes at the water/oxide interface.

Thus, the promoted arsenate adsorption in alkaline $\mathrm{pH}$ range, with increasing ionic strength, could be explained as follows. The adsorption of $\operatorname{As}(\mathrm{V})$ in an inner-sphere complexation manner increases the net negative charge of solid surfaces. A necessary consequence of surface negative charge buildup is the co-adsorption of cations. The increase of $\mathrm{NaNO}_{3}$ concentration in the solution can provide more $\mathrm{Na}^{+}$cations, which are available to compensate the surface negative charge generated by specific adsorption of $\mathrm{As}(\mathrm{V})$. This favored the $\mathrm{As}(\mathrm{V})$ anions adsorption and resulted in a greater adsorption.

\subsection{Zeta potential and FTIR measurements}

Specific adsorption of anions makes the surface of oxides more negatively charged, which results in a shift of the isoelectric point of adsorbent to a lower $\mathrm{pH}$ value [20,21]. A lower isoelectric point of the system should be therefore observed, if arsenate was specifically adsorbed on the Fe-Mn binary oxide. The zeta potentials of the Fe-Mn binary oxide suspensions before and after arsenate adsorption were measured and presented in Fig. 4. The Fe-Mn binary oxide was found to have an isoelectric point of about 6.0. As predicted, this value decreased to about 4.5 when arsenic anions were adsorbed. It is clear that the presence of arsenate anions makes the adsorbent surface more negatively charged. Specific adsorption rather than a purely electrostastic interaction could be deduced from the drop of isoelectric point at the aqueous arsenate/Fe-Mn binary oxide interface.

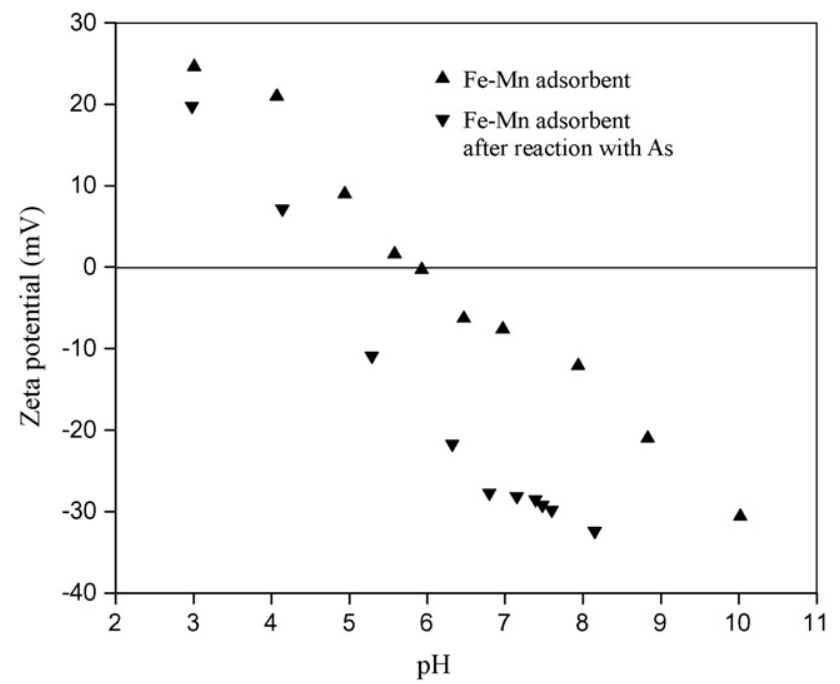

Fig. 4. Zeta potential of Fe-Mn binary oxide before and after reaction with $\mathrm{As}(\mathrm{V})$. $\mathrm{As}(\mathrm{V})$ concentration was $10 \mathrm{mg} / \mathrm{L}$ and adsorbent content was $200 \mathrm{mg} / \mathrm{L}$. 
More useful information about the interaction between aqueous arsenat and solid Fe-Mn binary oxide can be provided by the FTIR technique. According to Stumm [22], there are usually occurring metal hydroxyl groups on the surface of many metal oxides, which are the most abundant and active adsorption sites for adsorbate and can be detected by IR spectroscopy. IR spectroscopy has therefore been used to investigate the surface structures and the mechanism of adsorption.

The FTIR spectra of Fe-Mn binary oxide is obtained with the $\mathrm{KBr}$-pressed disk technique and is shown in Fig. 5. It is noted that infrared spectra of the adsorbent was earlier given and discussed [23]. For the Fe-Mn binary oxide sample, the band at $1625 \mathrm{~cm}^{-1}$ was assigned to the deformation of water molecules and indicated the presence of physisorbed water on the oxides; the peak at $1384 \mathrm{~cm}^{-1}$ was ascribed to the vibration of $\mathrm{NO}_{3}{ }^{-}$because sodium nitrate was used to adjust the solution ion strength; three peaks at 1127, 1047 and $974 \mathrm{~cm}^{-1}$ are due primarily to the bending vibration of hydroxyl groups of iron (hydr)oxides (Fe-OH) vibration [24].

The vibration models associated with the stretching and bending motions of $\mathrm{Fe}-\mathrm{OH}$ groups are sensitive to the presence of adsorbed anions. FTIR spectra of the Fe-Mn binary oxide after reaction with arsenic solutions containing $1-50 \mathrm{mg} / \mathrm{L}$ of $\mathrm{As}(\mathrm{V})$ at an initial $\mathrm{pH}$ of 6.9 for $24 \mathrm{~h}$ were collected and also shown in Fig. 5. It can be clearly seen that the $\mathrm{Fe}-\mathrm{OH}$ bending bands (peaks at 1127, 1047 and $974 \mathrm{~cm}^{-1}$ ) weakened gradually, while a new band, corresponding to As-O stretching vibration [24], appeared at $820 \mathrm{~cm}^{-1}$ and its intensity increased with the increase of $\mathrm{As}(\mathrm{V})$ concentration. This indicates that the $\mathrm{As}(\mathrm{V})$ is bound as a surface complex and not as a precipitated solid phase. The peaks at 1127,1047 and $974 \mathrm{~cm}^{-1}$ were almost disappeared when the concentration of $\mathrm{As}(\mathrm{V})$ reached $50 \mathrm{mg} / \mathrm{L}$. An increase in solution $\mathrm{pH}$ value was also observed after As(V) adsorption. From the FTIR analysis, it could be concluded that specific adsorption must occur at the aqueous arsenate/Fe-Mn binary oxide interface and the replacement of surface hydroxyl groups by the $\mathrm{As}(\mathrm{V})$ species is the main arsenate adsorption mechanism.

\subsection{Effect of coexisting ions on arsenate adsorption}

From above, the arsenate removal by the Fe-Mn binary oxide was mainly realized by forming surface complexes at the active sites on the surface of the adsorbent. Coexisting ions such as phosphate, bicarbonate, silicate, sulfate, chloride, calcium and magnesium are generally present in groundwater, and could interfere in the uptake

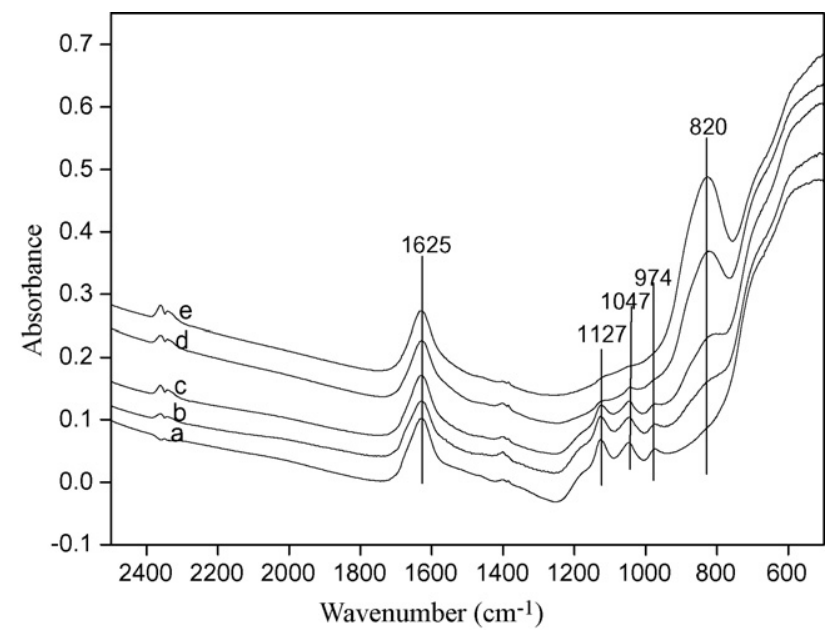

Fig. 5. FTIR spectra of Fe-Mn binary oxide (a) and after treatment in aqueous solutions of four different As(V) concentrations, (b) $1 \mathrm{mg} / \mathrm{L}$, (c) $5 \mathrm{mg} / \mathrm{L}$, (d) $20 \mathrm{mg} / \mathrm{L}$ and (e) $50 \mathrm{mg} / \mathrm{L}$
Table 3

Effect of coexisting ions on arsenate adsorption.

\begin{tabular}{llllllll}
\hline \multirow{2}{*}{ Concentration } & \multicolumn{7}{l}{ Percentage removal of $\mathrm{As}(\mathrm{V})$} \\
\cline { 2 - 7 } & $\mathrm{Cl}^{-}$ & $\mathrm{SO}_{4}{ }^{2-}$ & $\mathrm{CO}_{3}{ }^{2-}$ & $\mathrm{SiO}_{3}{ }^{2-}$ & $\mathrm{PO}_{4}{ }^{3-}$ & $\mathrm{Mg}^{2+}$ & $\mathrm{Ca}^{2+}$ \\
\hline $0.1 \mathrm{mM}$ & 91.3 & 91.5 & 87.7 & 86.2 & 76.3 & 92.5 & 92.8 \\
$1 \mathrm{mM}$ & 90.4 & 90.9 & 81.2 & 76.3 & 55.4 & 94.9 & 95.8 \\
$10 \mathrm{mM}$ & 90.2 & 90 & 80.6 & 50.3 & 43.7 & 96.1 & 97.9 \\
\hline
\end{tabular}

of arsenate by adsorbent through competitive binding or complexation. To investigate the effect of coexisting ions on the adsorption of $\mathrm{As}(\mathrm{V})$, these ions were added at three concentration levels (0.1, 1.0 and $10 \mathrm{mM}$ ) to arsenic solutions and the arsenic removal was studied at fixed $\mathrm{pH}$ of $6.9 \pm 0.1$. The experimental results were listed in Table 3.

It is clear that the coexisting $\mathrm{Cl}^{-}$and $\mathrm{SO}_{4}{ }^{2-}$ had no significant influence on $\mathrm{As}(\mathrm{V})$ removal and the presence of $\mathrm{CO}_{3}{ }^{2-}$ decreased the removal of $\mathrm{As}(\mathrm{V})$ a little. However, the coexisting oxyanions of $\mathrm{SiO}_{3}{ }^{2-}$ and $\mathrm{PO}_{4}{ }^{3-}$ hindered greatly the adsorption of $\mathrm{As}(\mathrm{V})$ and the percentage of $\mathrm{As}(\mathrm{V})$ removal reduced markedly with the presence of these anions. Among all the anions, phosphate caused the greatest percentage decrease in arsenic removal at each concentration level. This high interfering effect of phosphate in the arsenate removal could be due to the strong competition for the binding sites of the adsorbent between the phosphate and arsenate. Phosphate element and arsenic element are located in the same main group, and the molecular structure of phosphate ion is very similar to that of arsenic ion. Thus, the present phosphate ions must strongly compete with arsenate ions for adsorptive sites on the surface of Fe-Mn binary oxide. On the contrary, the presence of cations of $\mathrm{Ca}^{2+}$ and $\mathrm{Mg}^{2+}$ enhanced the adsorption of $\mathrm{As}(\mathrm{V})$. And the removal percentage increased with the increase in concentrations of these two cations. This can be explained as follows. The present cations could be adsorbed by the adsorbent and effectively compensate the surface negative charge generated by specific adsorption of $\mathrm{As}(\mathrm{V})$, which favored the $\mathrm{As}(\mathrm{V})$ anions adsorption. These results indicate that the adsorbent is promising to be used in real groundwater.

\section{Conclusions}

The Fe-Mn binary oxide adsorbent prepared by a simultaneous oxidation and coprecipitation method had a higher adsorption capacity towards $\mathrm{As}(\mathrm{V})$ than that of pure amorphous FeOOH. This may be due to its higher surface area $\left(265 \mathrm{~m}^{2} / \mathrm{g}\right)$ and pore volume $\left(0.47 \mathrm{~cm}^{3} / \mathrm{g}\right)$. The $\mathrm{As}(\mathrm{V})$ adsorption process on the Fe-Mn binary oxide is endothermic in nature and the increase of temperature is favoring its adsorption. The increase in ionic strength of the solution resulted in a slight increase in the $\mathrm{As}(\mathrm{V})$ adsorption, which suggested that $\mathrm{As}(\mathrm{V})$ anions might form inner-sphere surface complexes at the water/oxide interface. The Zeta potential and FTIR analysis confirmed further the formation of inner-sphere surface complexes between $\mathrm{As}(\mathrm{V})$ anions and the surface of Fe-Mn binary oxide. Among the tested anions, chloride and sulfate had no significant effect on arsenic removal, silicate reduced remarkably the $\mathrm{As}(\mathrm{V})$ removal, especially at high concentration and phosphate was the greatest competitor with arsenate for adsorptive sites on the adsorbent. On the contrary, the presence of cations of $\mathrm{Ca}^{2+}$ and $\mathrm{Mg}^{2+}$ enhanced the adsorption of $\mathrm{As}(\mathrm{V})$. The investigation of the adsorbent's application in practical water treatment is very necessary and now undergoing.

\section{Acknowledgements}

This work was financially supported by the Funds for Creative Research Groups of China (Grant No. 50621804) and the National Natural Science Foundation of China (Grant No. 20577063). 


\section{References}

[1] J.F. Ferguson, J. Gavis, A review of the arsenic cycle in nature waters, Water Res. 6 (1972) 1259-1274.

[2] P.L. Smedley, D.G. Kinniburgh, A review of the source, behavior and distribution of arsenic in natural waters, Appl. Geochem. 17 (2002) 517-568.

[3] L.C. Roberts, S.J. Hug, T. Ruettimann, A.W. Khan, M.T. Rahman, Arsenic removal with iron(II) and iron(III) in waters with high silicate and phosphate concentrations, Environ. Sci. Technol. 38 (2004) 307-315.

[4] M. Berg, H.C. Tran, T.C. Nguyen, H.V. Pham, R. Schertenleib, W. Giger, Arsenic contamination of groundwater and drinking water in Vietnam: a human health threat, Environ. Sci. Technol. 35 (2001) 2621-2626.

[5] D. Mohan, C.U. Pittman Jr., Arsenic removal from water/wastewater using adsorbents-a critical review, J. Hazard. Mater. 142 (2007) 1-53.

[6] M.L. Pierce, C.B. Moore, Adsorption of arsenite and arsenate on amorphous iron hydroxide, Water Res. 16 (1982) 1247-1253.

[7] S. Dixit, J.G. Hering, Comparison of arsenic(V) and arsenic(III) sorption onto iron oxide minerals: implications for arsenic mobility, Environ. Sci. Technol. 37 (2003) 4182-4189.

[8] M.J. Haron, W.M.Z. Wan Yunus, N.L. Yong, S. Tokunaga, Sorption of arsenate and arsenate anions by iron(III)-poly(hydroxamic acid) complex, Chemosphere 39 (1999) 2459-2466.

[9] Y.Zhang, M. Yang, X. Huang, Arsenic(V) removal with a Ce(IV)-doped iron oxide adsorbent, Chemosphere 51 (2003) 945-952.

[10] D. Mishra, J. Farrell, Evaluation of mixed valent iron oxides as reactive adsorbents for arsenic removal, Environ. Sci. Technol. 39 (2005) 9689-9694.

[11] G.S. Zhang, J.H. Qu, H.J. Liu, R.P. Liu, R.C. Wu, Preparation and evaluation of a novel Fe-Mn binary oxide adsorbent for effective arsenite removal, Water Res. 41 (2007) 1921-1928.

[12] G.A. Waychunas, B.A. Rea, C.C. Fuller, J.A. Davis, Surface chemistry of ferrihydrite. 1. EXAFS studies of the geometry of coprecipitated and adsorbed arsenate, Geochim. Cosmochim. Acta 57 (1993) 2251-2269.
[13] X.H. Sun, H.E. Doner, An investigation of arsenite and arsenite bonding structures on goethite by FTIR, Soil Sci. 161 (1996) 865-872.

[14] S. Goldberg, C.T. Johnston, Mechanisms of Arsenic Adsorption on Amorphous Oxides Evaluated Using Macroscopic Measurements, Vibrational Spectroscopy, and Surface Complexation Modeling, J. Colloid Interface Sci. 234 (2001) 204-216.

[15] X.H. Guan, J.M. Wang, C.C. Chusuei, Removal of arsenic from water using granular ferric hydroxide: macroscopic and microscopic studies, J. Hazard. Mater 156 (2008) 178-185.

[16] F.J. Hingston, R.J. Atkinson, A.M. Posner, J.P. Quirk, Specific adsorption of anions, Nature 215 (1967) 1459-1461.

[17] S.A. Crosby, D.R. Glasson, A.H. Cuttler, I. Butler, D.R. Turner, M. Whitfield, G.E. Millward, Surface areas and porosities of iron(III)- and iron(II)-derived oxyhydroxides, Environ. Sci. Technol. 17 (1983) 709-713.

[18] E.A. Deliyanni, D.N. Bakoyannakis, A.I. Zouboulis, K.A. Matis, Sorption of As(V) ions by akaganeite-type nanocrystals, Chemosphere 50 (2003) 155-163.

[19] M.B. McBride, A critique of diffuse double layer models applied to colloid and surface chemistry, Clays Clay Miner. 45 (1997) 598-608.

[20] W. Stumm, J.J. Morgan, Aquatic Chemistry: Chemical Equilibria and Rates in Natural Waters, third ed., John-Wiley and Sons, New York, 1996.

[21] T.H. Hsia, S.L. Lo, C.F. Lin, D.Y. Lee, Characterization of arsenate adsorption on hydrous iron oxide using chemical and physical methods, Colloids Surf. A: Physicochem. Eng. Asp. 85 (1994) 1-7.

[22] W. Stumm, Chemistry of the Solid-Water Interface, John-Wiley and Sons, New York, 1992.

[23] G.S. Zhang, J.H. Qu, H.J. Liu, R.P. Liu, G.T. Li, Removal mechanism of As(III) by a novel Fe-Mn binary oxide adsorbent: oxidation and sorption, Environ. Sci. Technol. 41 (2007) 4613-4619.

[24] Y. Zhang, M. Yang, X.M. Dou, H. He, D.S. Wang, Arsenate adsorption on an Fe-Ce bimetal oxide adsorbent: role of surface properties, Environ. Sci. Technol. 39 (2005) 7246-7253. 